\title{
Cesiation in highly efficient surface plasma sources
}

\author{
V. Dudnikov and R. P. Johnson \\ Muons, Inc., Batavia, Illinois 60150, USA \\ (Received 22 January 2011; published 25 May 2011)
}

\begin{abstract}
Novel modifications of $\mathrm{H}^{-} / \mathrm{D}^{-}$source designs have been proposed. New sources under development include advanced versions of a compact surface plasma source which will efficiently generate brighter beam in noiseless discharge, deliver significantly increased (up to $20 \mathrm{~mA}$ ) average current with better electrode cooling using new materials, and have significantly extended lifetime, fast beam chopping capability, and reduced cesium loss. Related ion sources that use cesium are described and an improved cesiation procedure for reproducible production of high efficiency $\mathrm{H}^{-}$ion generation is considered.
\end{abstract}

DOI: 10.1103/PhysRevSTAB.14.054801

PACS numbers: 29.20.Ej, 29.25.Ni, 41.75.Cn

\section{INTRODUCTION}

The problem of intense, high brightness negative ion beam production for accelerators (including nuclear polarized negative ions) and for neutral beam injection was solved, in general, by the discovery of the "cesiation effect," whereby $\mathrm{H}^{-}$emission is enhanced while coextracted electron current is simultaneously decreased below the $\mathrm{H}^{-}$ current by a small admixture of cesium vapor into the gas discharge ion source [1]. In subsequent experiments [2-5], it was demonstrated that cesium adsorption decreases the surface work function, enhances secondary emission of negative ions, and catalyzes the surface plasma generation (SPG) of negative ions caused by the interaction of the plasma with the electrode surface. Ion sources based on this process have been named surface-plasma negative ion sources (SPS). The high brightness SPS with Penning discharge (PD) was developed and described in [4]. During the past 30 years, proton accelerators with charge-exchange injection have used some versions of the compact SPS (cesiated magnetron SPS and cesiated Penning discharge SPS) or large volume (LV) SPS (surface converter SPS). Reviews of SPS development and their use in accelerators and in neutral beam injectors are presented in Refs. [3,5-8]. For new accelerator projects it is necessary to develop negative ion sources with significantly increased average current, increased brightness, and extended operation time [8]. In response to these challenges, advanced versions of magnetron SPS and PD SPS are proposed and considered.

\section{COMPACT SPS}

\section{A. Magnetron (planotron)}

The cesiated magnetron (planotron) SPS was invented by Dudnikov [1] in BINP, Novosibirsk, and developed with

Published by the American Physical Society under the terms of the Creative Commons Attribution 3.0 License. Further distribution of this work must maintain attribution to the author(s) and the published article's title, journal citation, and DOI.
Belchenko and Dimov up to $1 \mathrm{~A}$ of $\mathrm{H}^{-}$current [5]. The magnetron design, used in FNAL, BNL, ANL, and DESY, was developed and adapted by Schmidt, where it has been operational in the Tevatron accelerator complex since 1978 [6]. The efficiency of $\mathrm{H}^{-}$generation and lifetime were improved significantly by geometrical focusing developed by Dudnikov [3,9]. The peak current of the $\mathrm{H}^{-}$ion beam at the exit of the $750 \mathrm{keV}$ accelerator column is $I_{b} \sim 70 \mathrm{~mA}$ with extraction voltage $U_{\mathrm{ex}}=25 \mathrm{kV}$ with a beam pulse length $T=0.075 \mathrm{~ms}$ at $15 \mathrm{~Hz}$. The design of the magnetron with spherical focusing (developed by Alessi in BNL) is shown in Fig. 1 (recently it was improved by machining a cylindrical groove around the entire cathode). This design is optimized for low duty factor $(d f)$ operation with a low average discharge power of $P \sim 50 \mathrm{~W}$.

In these magnetron designs, the optimum cathode temperature $T_{c} \sim 500^{\circ} \mathrm{C}$ and the anode temperature $T_{a} \sim$ $250^{\circ} \mathrm{C}$ are relative high. For this reason, the cathode and anode are thermally insulated from the air-cooled baseplate by Macor machinable ceramic. The cathode is supported by insulators made of machinable ceramic Macor with very low thermal conductivity $(\sim 0.014 \mathrm{~W} / \mathrm{cm} \mathrm{K})$ and with a weak contact between parts. The anode cover (plasma plate), which contains the emission aperture, is very thin and it is thermally insulated. The small cathode anode gap $(\sim 1 \mathrm{~mm})$ is enough to hold the discharge voltage without short circuiting during long term operation. This design performs very well for production of up to $100 \mathrm{~mA}$ pulses with $d f$ up to $0.5 \%$. In discharge without cesium, the discharge voltage is $\sim 600 \mathrm{~V}$ and sputtering is very significant. With low voltage discharge $\left(U_{d} \sim 100 \mathrm{~V}\right)$ and optimized cesiation, electrode sputtering caused by the discharge is very low. A more significant limitation of this compact surface plasma source (CSPS) lifetime is due to cathode sputtering caused by back-accelerated positive ions, which stems from the use of a simple diode extraction system.

Nevertheless, this very compact and simple version of the magnetron has worked sufficiently well for high voltage preinjectors and radio frequency quadrupoles 
hollow cathode

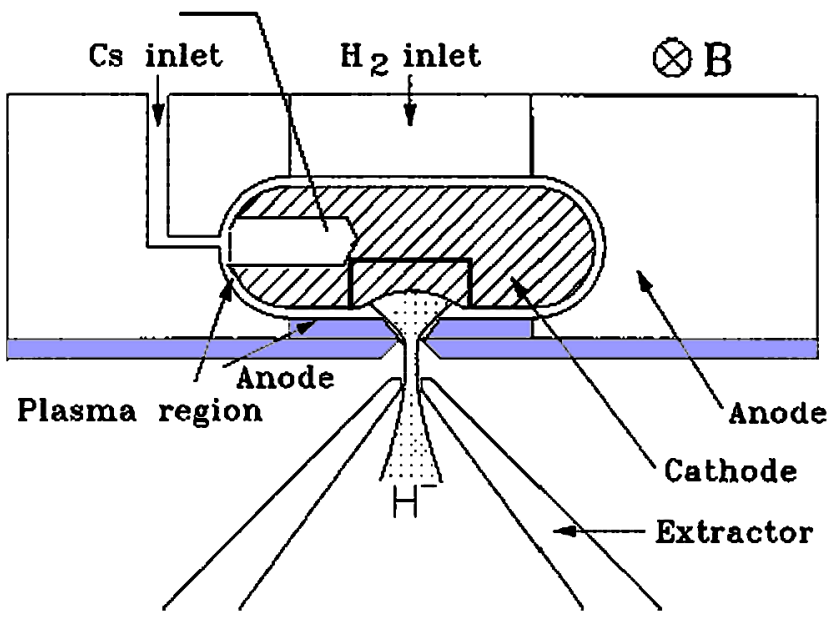

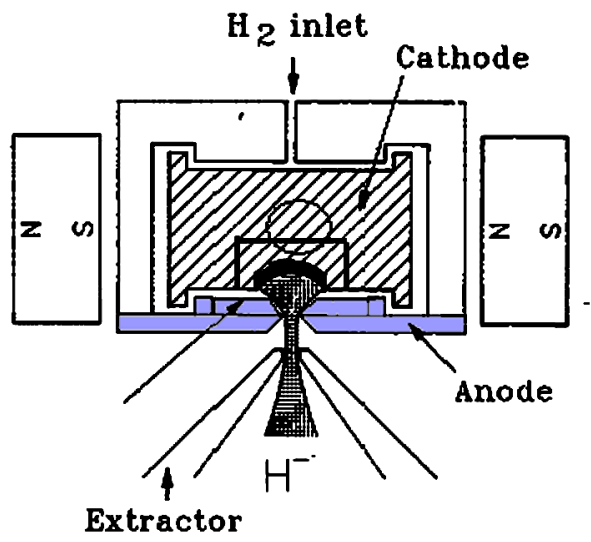

FIG. 1. Advanced version of magnetron with hollow cathode for suppression of discharge noise.

(RFQs). With noisy discharge the effective transverse ion temperature is relatively high $\sim 10 \mathrm{eV}$. The normalized rms emittance with a $10 \mathrm{~mm}$ long slit is $\varepsilon_{n y} \sim 0.5$ ( $\pi \mathrm{mm} \mathrm{mr}$ ). The magnetron has many years of operational accelerator experience. In all cases, magnetron sources are able to satisfy the requirements of the accelerators, and in most cases run at the space-charge limit for extraction.

All magnetron sources manage to provide beams for up to nine months (up to $3.6 \times 10^{8}$ pulses $\sim 2$ A hours) per year before requiring dismounting and cleaning. In the HERA linac, a cesiated magnetron was tested for continuous operation for 32 months with low cesium consumption [7]. The duty factor can be increased by replacing the Macor insulators by AlN ceramic, which has much higher thermal conductivity. The magnetron with cathode cooling by compressed air for larger average current production is described by Peters in [7].

The magnetron beam quality can be improved by suppressing discharge noise, which will increase beam brightness. One possibility for noise suppression is to use a hollow cathode as shown in Fig. 1. This technique has been successfully used in semiplanotrons [3,9-11] for discharge noise suppression.

Our newly proposed configuration of an advanced magnetron SPS for pulsed and DC high average current production is shown in Fig. 2. The discharge system consists of a cathode (4) with a racetrack discharge gap between cathode and anode (1), as in the magnetron planotron. The cathode configuration has the same shape as in the semiplanotrons $[3,9]$, but it is supported by high
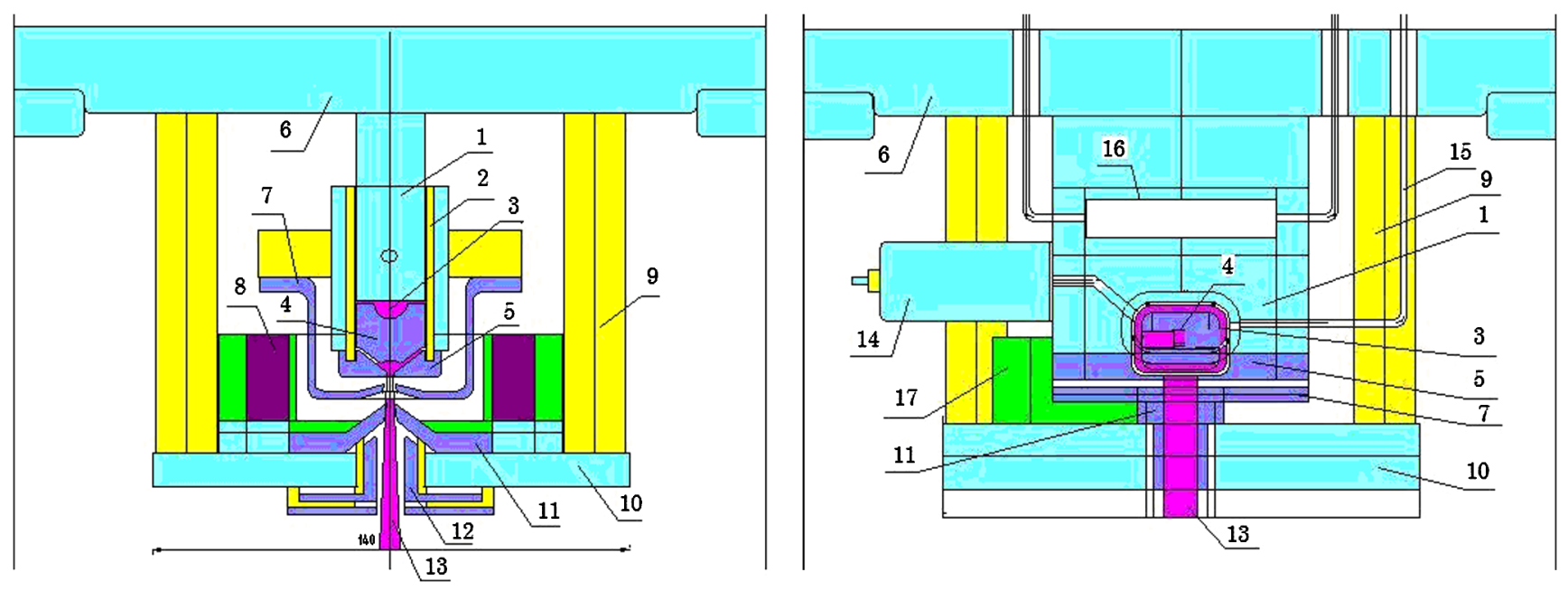

FIG. 2. Schematic of upgraded magnetron (planotron) SPS. Left: Cross section along the magnetic field. Right: Cross section perpendicular to the magnetic field. (1) Cooled anode; (2) high thermoconductive insulator ALN; (3) discharge gap; (4) cathode with channel for HCD; (5) plasma plate with emission aperture; (6) cooled high voltage flange; (7) first extractor-electron collector; (8) permanent magnet with magnetic poles and yoke; (9) high voltage insulators; (10) baseplate; (11) grounded extractor; (12) suppressor of positive ions; (13) ion beam; (14) gas valve; (15) cesium delivery system; (16) cooling channel; (17) magnetic yoke. 
conductive insulator plates from the sides, as in the magnetron. A narrow cylindrical groove serves for discharge and ion flux focusing. A cylindrical channel for hollow cathode discharge (HCD) is used for stabilization as in the semiplanotron $[3,9,11]$. A cathode with spherical geometric focusing and small circular emission aperture (as shown in Fig. 1) can be used in this magnetron design also. A good thermal contact with high thermoconductive insulators (2) made from AlN will be used for cathode cooling. The plasma plate (5) has large mass and good thermal contact with the cooled anode, as in the BINP Penning discharge CSPS [3,12]. For reproducible cesiation it is important to be able to regularly clean the electrode and to reactivate it by heating to high temperature.

In pulsed mode a fast gas valve (14), described in [13], injects calibrated gas portions into a small discharge volume. For long term operation, cesium will be injected into the discharge volume by an external cesium delivery system (15), as in the FNAL magnetron [6]. Improved cooling will improve cesium recycling on the electrode surface and will prevent electrode sputtering and flake formation. With this improved cooling, the average discharge power can be increased significantly above that of existing CSPS. Adsorption of hydrogen and cesium shields the cathode material from sputtering by ions. Fast ionization of cesium atoms and of sputtered cathode material decreases cathode sputtering by recycling [5]. Discharge with reversed polarity will be used for anode surface activation by cesium ion implantation and for anode cleaning. Discharge with $\mathrm{NF}_{3}$ gas is proved as an efficient method for the flakes gasification.

With a small emission aperture, it is possible to have high enough gas density for complete transformation of fast primary $\mathrm{H}^{-}$to cold $\mathrm{H}^{-}$by resonant charge-exchange cooling. This will help provide a stable noiseless discharge, as in the semiplanotron SPS. These conditions produce high brightness with an emission current density of $\sim 1 \mathrm{~A} / \mathrm{cm}^{2}$. The flux of coextracted electrons must be less than the $\mathrm{H}^{-}$current. With high voltage extraction (i.e. $\sim 50 \mathrm{keV}$ ), it is good to have the first step of extraction (7) with relatively low voltage $(7-15 \mathrm{kV})$. The magnetic system has special magnetic inserts near the extractor to create concave field lines. This will provide conditions for removal of electrons from the extractor gap without trapping them in the gap. The second extractor gap will provide the remaining part of the extractor voltage (up to $60 \mathrm{kV}$ for use in an RFQ injector or for tandem and cyclotron injection). For further acceleration, it is possible to use an additional acceleration gap.

The suppression electrode (12) has a positive voltage to suppress penetration of positive ions from the beam to the extractor. This prevents electrode sputtering by backaccelerated positive ions. For further beam transportation, magnetic focusing with partial space-charge neutralization [as in many CSPS (e.g., BNL, ANL, FNAL)], or strong electrostatic focusing (as in the SNS LVSPS, or DC PD SPS at BINP) could be used. For beam chopping that is necessary for injection into synchrotrons, it is possible to use a pulsed transverse electric field parallel to the magnetic field, which is applied between two separated plates of the suppression electrode (12) to deflect beam from the aperture. This possibility was tested in the Fermilab magnetron and was discussed in the report of Moehs [14].

An improved discharge configuration and insulators with enhanced thermal conductivity, such as aluminum nitride (AlN), will be used. (AlN has the thermal conductivity up to $K=2.5 \mathrm{~W} / \mathrm{cm}-\mathrm{K}$ which is $\sim 150$ times higher than Macor.) We have tested samples of AlN plates provided by Belander Industrial Group, Inc. (ceramic plates, $2.2 \times 2.2 \times 0.11 \mathrm{in}^{3}$ ).

Other important SPS components are the permanent magnets. Blocks of nickel coated NdBFe permanent magnets delivered by Rochester Magnet Corp. were tested for long term operation in vacuum with a hydrogen discharge. With proper cooling and care to protect the coating from mechanical damage, these magnets passed long term tests. However, after its nickel coating was damaged at one spot, one magnet was destroyed after a relatively short exposure to a hydrogen environment.

New materials and a new design will make it possible to increase the average beam current and to extend the lifetime in ampere-hours. With $\mathrm{H}^{-}$production efficiency of about $60 \mathrm{~mA} / \mathrm{kW}$, an average beam current $I \sim 20 \mathrm{~mA}$ can be produced with the average discharge power $P \sim 0.3 \mathrm{~kW}$, which can be removed in the design shown in Fig. 2. The lifetime will be extended by suppressing cathode sputtering by back-accelerated positive ions, by using a tungsten cathode with lower sputtering, by fabrication of special pockets for sputtered material collection, and by flakes gasification in $\mathrm{NF}_{3}$ discharge.

\section{B. Penning discharge SPS}

The Penning discharge SPS (shown in Fig. 3) uses a discharge with an anode window, surrounded by cathodes at each end, aligned along the magnetic field. Extraction of the ions is through a slit in the anode perpendicular to the magnetic field. The Penning discharge SPS was invented by Dudnikov in BINP [4]. It has had a long history of development at LANL $[8,12,15]$. Now it is successfully used at ISIS RAL $[16,17]$ and is under development for the Chinese SNS. The fundamental difference between the magnetron and Penning sources is that, in the magnetron, $\mathrm{H}^{-}$ions produced at the cathode are directly extracted, while in the Penning source the ions must undergo a charge-exchange process or scattering on atomic hydrogen to reach the emission aperture since there is no direct path from the cathode to the aperture. Discharge noise can be eliminated in a cesiated Penning SPS by optimizing the magnetic field and gas density or using a small admixture of heavier gas $\left(\mathrm{N}_{2}\right.$ in [12]). In this regard, emittance measurements have 


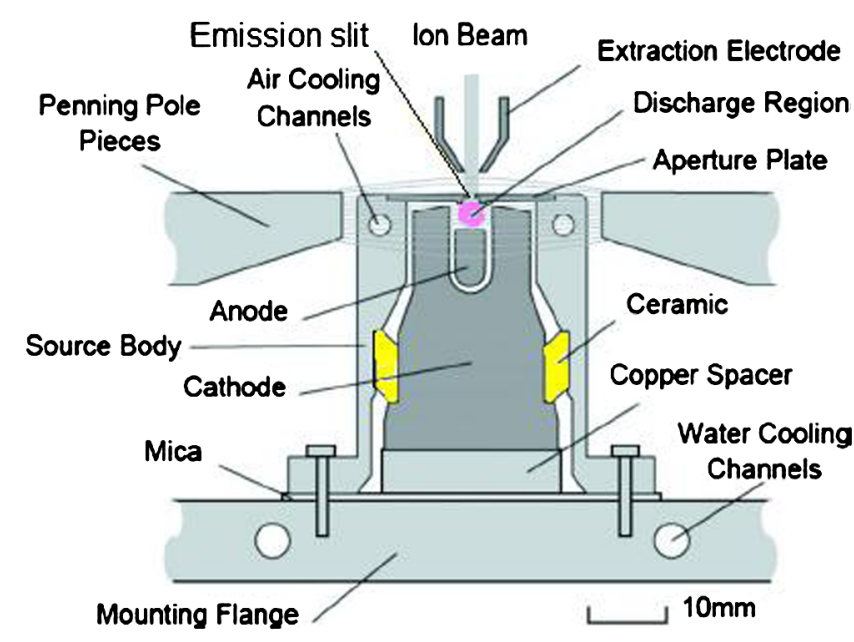

FIG. 3. Schematic of RAL ISIS version of Penning discharge SPS [17].

shown the Penning SPS always has higher brightness than the magnetron (and other ion sources). The effective ion temperature can be as low as $T_{i} \sim 1 \mathrm{eV}$.

The LANL 1X Penning and ISIS Penning SPS have essentially the same discharge chamber dimensions as in the first version of the Dudnikov-type SPS [4]. The RAL Penning SPS that is in use at the ISIS facility delivered $35 \mathrm{~mA}$ (discharge $d f \sim 2.5 \%$, beam $d f \sim 1 \%$ ) after $650 \mathrm{kV}$ preacceleration for a period up to 50 days $[8,17]$ (the lifetime is 25 days with $50 \mathrm{~mA}$ ).

This version of SPS shown in Fig. 3 has limited cooling because the prototype was optimized for low $d f$ operation. The cathode cooling was improved by contact with a water cooled flange through a mica layer. But this layer has low thermal conductivity and limited heat transfer. The anode is cooled by air flow. However, the thin plasma plate that includes the emission slit has low thermal conductivity and is easily overheated. This ion source is currently under redevelopment at RAL for possible use on future high power accelerator projects. The development goals are $70 \mathrm{~mA} \mathrm{H}^{-}$current with a short pulse of $1.2 \mathrm{~ms}$ at $50 \mathrm{~Hz}$, and $70 \mathrm{~mA} \mathrm{H}^{-}$current with a long pulse of $2.5 \mathrm{~ms}$ for $50 / 3 \mathrm{~Hz}$. The design emittance ( $\mathrm{rms}$, normalized) is $<0.3$ ( $\pi \mathrm{mm} \mathrm{mr}$ ) with lifetime greater than 20 days $[8,17]$.

A Penning SPS for higher average current was built and tested at BINP by Dudnikov and coauthors [18]. Operation with beam current above $100 \mathrm{~mA}$ in $0.25 \mathrm{~ms}$ pulses with repetition rate of $100 \mathrm{~Hz}$ has been demonstrated for $>300$ hours $(d f=2.5 \%)$. Operation with a repetition rate of up to $400 \mathrm{~Hz}$ ( $d f 10 \%$ ) has been tested. Distinctive features of this Penning SPS compared with the ISIS source are its slightly larger discharge cell and more massive anode cover (plasma plate) with forced air or water cooling. The cathode has a strong pressed contact with a copper cooler. It is cooled by strong flow of water. A fast $(0.1 \mathrm{~ms})$ gas valve [13] is used to inject gas at a repetition rate up to $500 \mathrm{~Hz}$. Stable support of noiseless discharge has been established which is important for high brightness beam production.

At LANL, sources were designed and constructed applying plasma scaling laws and increasing two of the source dimensions by a factor 4 (the $4 \mathrm{X}$ source). This reduced the cathode power load from 16.7 to $2.24 \mathrm{~kW} / \mathrm{cm}^{2}$ while increasing the $\mathrm{H}^{-}$current from $160 \mathrm{~mA}\left(0.5 \times 10 \mathrm{~mm}^{2}\right.$ slit $)$ to $250 \mathrm{~mA}\left(2.8 \times 10 \mathrm{~mm}^{2}\right.$ slit) $[8,17]$. The measured rms normalized emittance is $0.15 \pi \mathrm{mm}$ mrd in the narrow slit dimension $(2.8 \mathrm{~mm})$. Emittance in the long slit dimension $(10 \mathrm{~mm})$ is $0.29 \pi \mathrm{mm} \mathrm{mr}$ for an unoptimized slit extraction system at $29 \mathrm{keV}$ extraction energy. It is possible that the last emittance increase, which affects only a small part of the beam, is connected with end effects of the slit. In this case, it can be improved by collimation.

Increased emission current density (up to $0.35 \mathrm{~A} / \mathrm{cm}^{2}$ ) of $\mathrm{H}^{-}$was produced in the Dudnikov-ype source with $\mathrm{LaB}_{6}$ cathodes without $\mathrm{Cs}$ after electrode activation by a high current discharge [19]. Later, increased emission current density was produced in a multicusp $\mathrm{H}^{-}$source with a hot $\mathrm{LaB}_{6}$ cathode [20,21], where surface-plasma $\mathrm{H}^{-}$generation was enhanced by high current discharge with negative biasing of the plasma electrode during electrode activation. This enhancement can be explained as due to the decrease of the surface work function connected with La deposition.

However, it was observed in many cases including [21] that in discharges with $\mathrm{LaB}_{6}$ cathodes, the "cesiation effect" is not as strong as with $\mathrm{W}$ or Mo hot or cold cathodes. Therefore, in [21] it was concluded that the work function of the surface coated with B, La, and $\mathrm{O}$ cannot be decreased by seeding Cs. Insufficient deoxidization of the molybdenum plasma electrode surface, caused by a temperature lower than $300^{\circ} \mathrm{C}$ due to the thermal conduction to the copper plate, is probably the cause of the lower $I_{\mathrm{H}}^{-}$. It is well known from work function research that a smaller work function can be produced by cesiation of the surface with a larger work function. By this reason the cesiation of surfaces with low work function deposited by lanthanum can produce only relative small improvement of work function.

\section{Advanced Penning discharge SPS}

The $\mathrm{H}^{-}$ion temperature $\mathrm{Ti}$ in Penning discharges can be $\sim 1 \mathrm{eV}[4,8]$. Accordingly, for an emission slit with length $2 l$, the normalized rms emittance $\varepsilon n=0.045 x l$ (Ti) ${ }^{1 / 2} \pi$ mm mrd can be $\sim 0.25 \pi \mathrm{mm} \mathrm{mr}$. The effective ion temperature in the transverse direction is about 3 times larger but the transverse slit size is smaller and so this emittance is smaller than $0.25 \pi \mathrm{mm} \mathrm{mr}$. The schematic of the proposed modified PD SPS is shown in Fig. 4. The design and operation of the proposed source are clear from the captions to Figs. 3-5.

In discharges with high plasma density and increased distance between cathode surfaces (1) and emission aperture, the $\mathrm{H}^{-}$ions from the cathode cannot reach the emission 


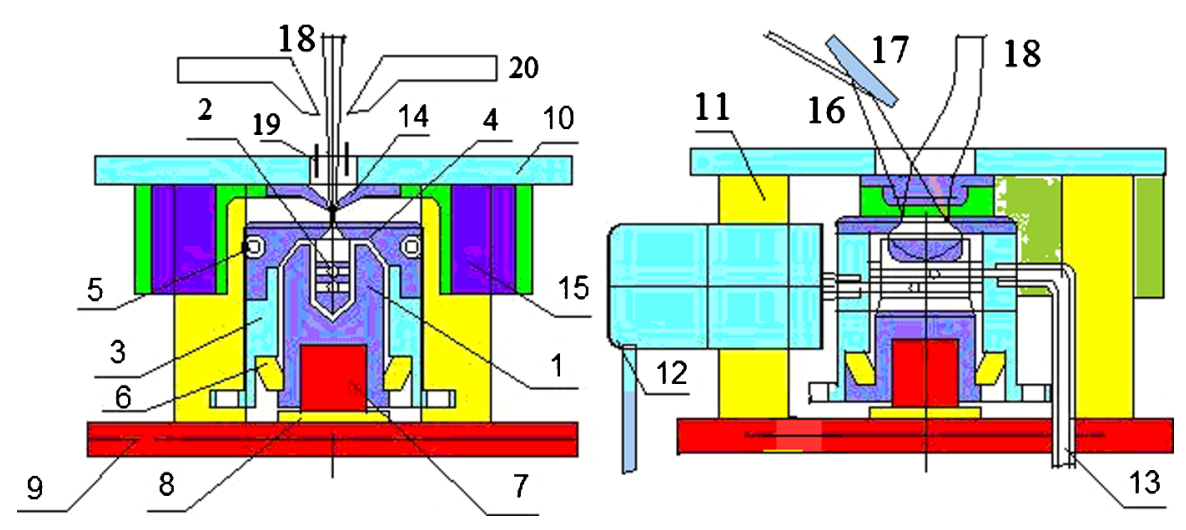

FIG. 4. Schematic of the upgraded version of the Penning discharge SPS for pulsed and cw chopped $\mathrm{H}^{-}$beam production. (1) cathode; (2) anode; (3) source body; (4) cooled plasma plate; (5) anode cooling; (6) cathode insulator; (7) cathode cooler; (8) thermal conductive insulator (AlN); (9) cooled flange; (10) baseplate; (11) high voltage insulators; (12) gas delivery system (pulsed valve); (13) cesium delivery system; (14) extractor; (15) magnet (SmCo) + coils; (16) laser beam for Cs diagnostic/trapping; (17) mirror; (18) negative ion beam; (19) suppressor/deflector; (20) accelerating electrode.

slit without destruction. In this case, the surface-plasma generation of $\mathrm{H}^{-}$on the plasma electrode (anode SPG) around the emission aperture is most important. In previous experiments it has been demonstrated that this anode SPG is efficient $(\sim 10 \mathrm{~mA} / \mathrm{kW})$. The cesium admixture decreases the work function of the cathode and anode to increase the secondary emission of electrons and negative ions. For stability of the optimal cesium film it is important to maintain the optimal surface temperature, which is easier for larger sources. The cesium concentration and conditions for SPG should be optimized on the plasma plate surface around the emission aperture. A more detailed drawing of the extraction/postacceleration system is shown in Fig. 5.

Slit extraction is very adequate for $\mathrm{H}^{-}$production by an anode SPG. Low ion temperature is preserved very well during slit extraction. The observed increased emittance along the slit [12] is due to aberrations that affect a small fraction of the beam extracted from the ends of the slit and can be decreased by collimation.

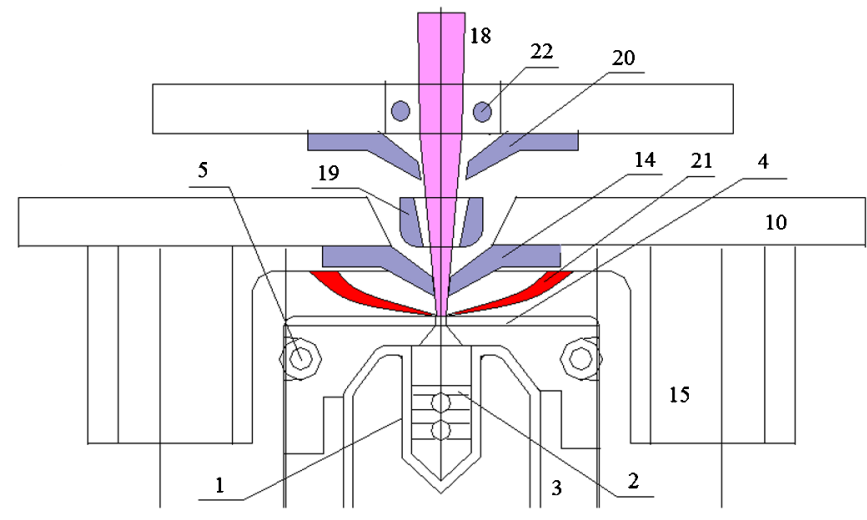

FIG. 5. Extraction system of PD SPS. (1) cathode; (2) anode; (3) source body; (4) cooled plasma plate; (5) anode cooling; (14) extractor; (15) magnet; (18) negative ion beam; (19) suppressor/ deflector; (20) acceleration electrode; (21) electron flux; (22) reflector.
A three or four electrode extraction system will be optimized to produce beam optics with minimum aberrations and low coextracted electron current. The electron flux (21) is collected along magnetic field lines to the electron dump. It is important to suppress the secondary emission of $\mathrm{H}^{-}$and cesium ions from the extractor. A suppression electrode (19) is used for collection of slow positive ions to prevent their acceleration into the discharge chamber which is important for suppression of electrode sputtering by these positive ions. Positive ions in the acceleration gap should be defocused by the electric field and collected. The reflector (22) is used to reflect positive ions generated in the $\mathrm{H}^{-}$beam.

All these comments are applicable to the DC Penning SPS discussed in publication [22]. The combination of proposed improvements can deliver high quality $\mathrm{H}^{-}$ beam with a pulse intensity $\sim 100 \mathrm{~mA}$ and with average current up to $20 \mathrm{~mA}$ at average discharge power of about $2 \mathrm{~kW}$. The lifetime of this SPS can be extended to $\sim 6 \mathrm{~A}$ hours ( $\sim 2000$ hours for $3 \mathrm{~mA}$ average beam current).

Cesium atom excitation by a resonant laser beam (16) will be used for effective suppression of cesium loss from the discharge chamber as disclosed in [23].

The first versions of CSPS for accelerators used magnetic beam focusing/deflection and a long low energy beam transportation (LEBT) to prevent cesium migration to the accelerator column or RFQ. Later it was demonstrated with real accelerators that a high voltage column can operate normally after $\sim 30 \mathrm{~g}$ of cesium have been deposited into a SPS [8]. It was also shown that with low cesium injection it is possible to use a simpler, more compact correctly designed electrostatic LEBT [22,24].

A newly proposed scheme of beam acceleration and focusing by transaxial lenses is shown in Fig. 6. A ribbon beam of $\mathrm{H}^{-}$(3) is extracted from the PD SPS (1) through the $1 \times 10 \mathrm{~mm}^{2}$ emission slit (2) by the extractor (4) in the field of the SPS magnet (5) as in previous versions of the 

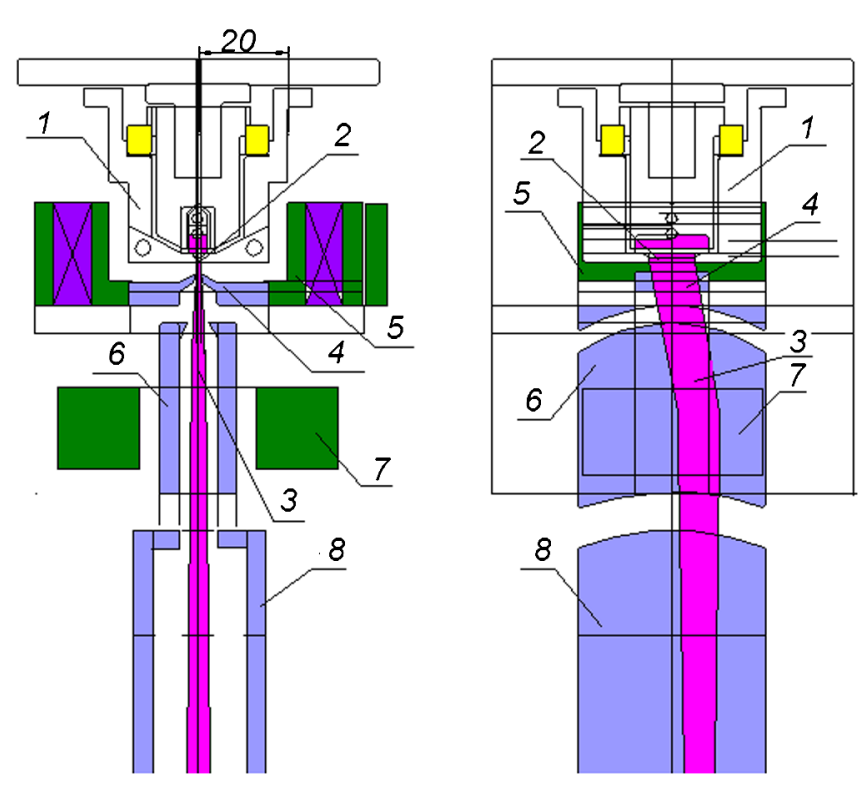

FIG. 6. PD SPS with transaxial lens focusing (left-cross section along magnetic field; right-cross section perpendicular to magnetic field). (1) PD SPS; (2) emission slit; (3) ion beam; (4) extraction electrode; (5) magnet of SPS; (6) grounded electrode of transaxial immersion lens; (7) compensating magnet; (8) first transaxial lens.

PD SPS [18]. The extracted beam (3) is further accelerated in the cylindrical gap between electrode (4) and electrode (6) serving as the transaxial electrostatic immersion lens. This lens has many parameters which can be used for independent optimization of the focusing properties in the perpendicular transverse directions. By varying the radius and center location of the cylindrical gap, it is possible to change the focusing force strength and its sign along the emission slit with little change to the beam focusing in the orthogonal direction.

The shape of the accelerating (decelerating) gap can be used for correction of aberrations. Shifting the lens plates can correct beam direction and position. The voltage between plates can be used for beam direction correction and for beam deflection. The compensating magnet (7) is used for restoring the beam direction, which is distorted by the SPS magnet (5). In the design of the extraction, focusing, and accelerating components, conditions for high vacuum discharges and electron trapping must be avoided.

Additional transaxial lenses in the gap between electrodes (6) and (8) can be used for additional beam focusing and defocusing for optimal matching with downstream accelerator structures such as an RFQ.

\section{ELECTRODE ACTIVATION IN A LARGE VOLUME SPS WITH SADDLE RF ANTENNA}

Efficient cesiation and long term operation with a very small quantity of cesium were accomplished in the SPS recently $[24,25] . \mathrm{H}^{-}$ion generation in a rf LV SPS with a saddle antenna was tested in Ref. [25]. A diagram of the rf SPS with saddle antenna and plasma gun igniter is shown in Fig. 7.

This SPS was assembled after a regular cleaning procedure using alcohol to remove alkali impurities and to transform their remains into stable compounds.

A strong transverse magnetic field was created by permanent magnets inside and below the collar for deflecting electrons.

The cesium transport line was heated but the Cs ampoule was not cracked. A grounded rf power supply with $\mathrm{rf}$ insulating transformer was used for these experiments. The beam current on the SNS test stand was measured using a toroidal beam current monitor and a calibrated Faraday cup, both located at the exit of the LEBT [24] similar to basic SNS rf sources.

After starting the rf discharge with $\mathrm{rf}$ power $P_{\mathrm{rf}}=$ $24 \mathrm{~kW}, 10 \mathrm{~Hz}, 0.3-0.4 \mathrm{~ms}$ at magnetic field $B=250 \mathrm{G}$, the initial beam current into Faraday cup $I_{\mathrm{fc}}=8 \mathrm{~mA}$ grows to $42 \mathrm{~mA}$ during four hours without cracking the cesium ampoule as shown by curve 1 (blue) in Fig. 8. At the same time, the extracted current (which includes electrons and back-accelerated positive ions in addition to the $\mathrm{H}^{-}$ions measured by the Faraday cup) decreased significantly. The initial current density $J \sim 20 \mathrm{~mA} / \mathrm{cm}^{2}$ generating with cleaned collar can be interpreted as volume generation but increase of $\mathrm{J}$ up to $100 \mathrm{~mA} / \mathrm{cm}^{2}$ with the same rf power must be interpreted as produced by SPG through the electrode activation by the accumulation of impurities with low ionization potential (ILIP) substances on the collar ionization surface. The $\mathrm{H}^{-}$current decreases linearly from 60 to $12 \mathrm{~mA}$ with decreasing magnetic field $\mathrm{B}$ from 250 to $50 \mathrm{G}$.

We believe that perfect "activation" was produced (without additional Cs) by the collection and trapping of traces of cesium compound remnants from SPS surfaces. Long conditioning is necessary because cesium is only slowly recovered from remnants. This slow accumulation demonstrates that the lifetime of these activating impurities on the collar can be very long. Nanograms of impurities are enough for enhancement of secondary emission of negative ions from the collar surface.

Stable operation of the tested prototype $\mathrm{rf}^{-}$SPS with the saddle antenna and longitudinal magnetic field up to the highest available rf power of $56 \mathrm{~kW}, 0.3 \mathrm{~ms}, 10 \mathrm{~Hz}$ was successfully demonstrated. With lower magnetic field, the rf discharge became unstable at gas flow $Q \sim 19 \mathrm{sccm}$. A beam current of $I_{\mathrm{fc}}=67 \mathrm{~mA}$ was observed with $\mathrm{rf}$ power of $P_{\mathrm{rf}}=56 \mathrm{~kW}$.

Variations of collar temperature (curve 3, green) can influence the $\mathrm{H}^{-}$beam current as seen in Fig. 8. Decreasing the collar temperature increases the $\mathrm{H}^{-}$current by increasing cesium adsorption. However, below the optimal temperature $\left(\sim 270^{\circ} \mathrm{C}\right)$ the $\mathrm{H}^{-}$current decreases, which can be interpreted as passing the minimum of the 


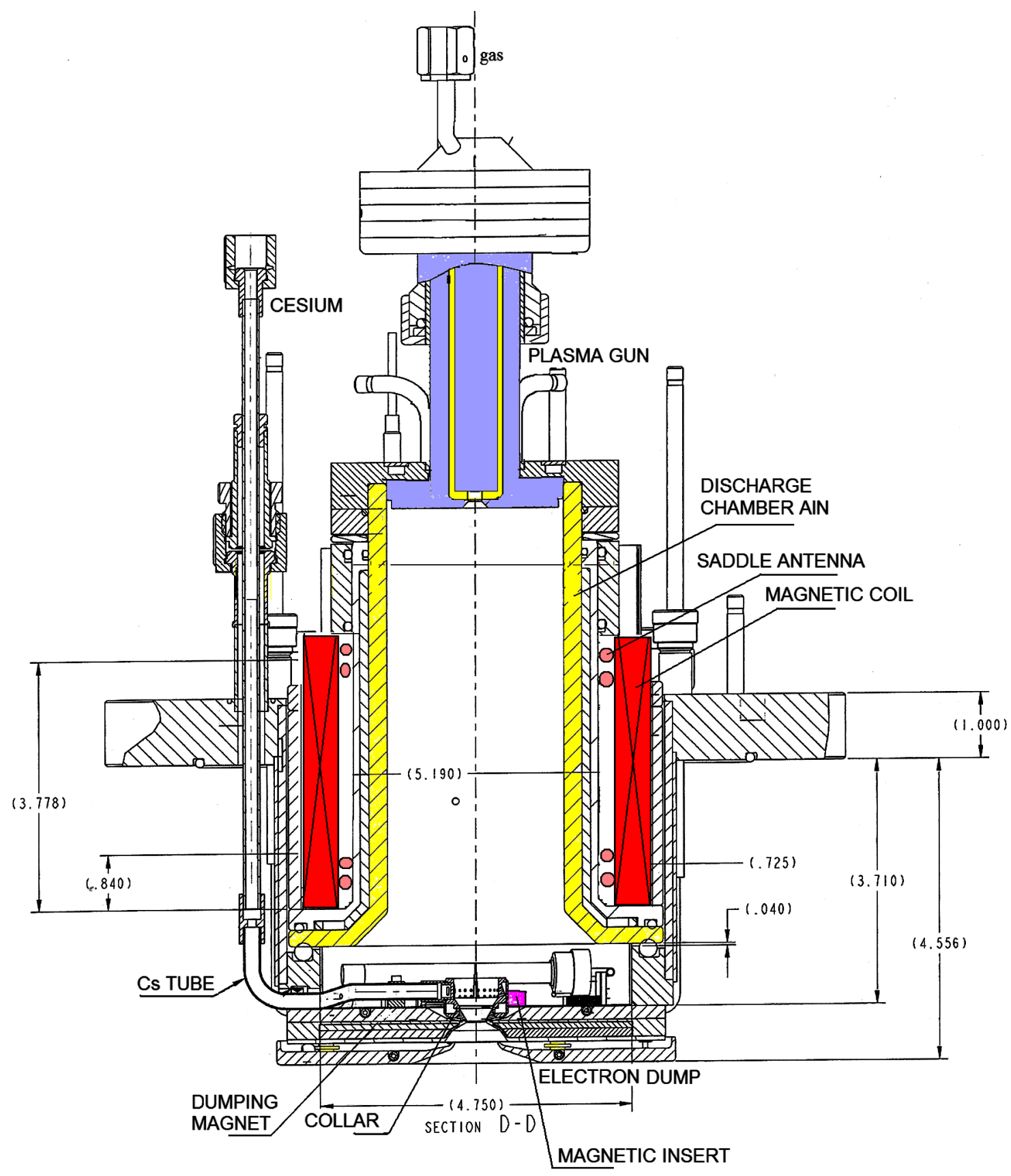

FIG. 7. Diagram of large volume SPS with saddle rf antenna, magnetic coil, and glow discharge plasma gun igniter (7 mm diameter emission aperture collar).

work function dependence on the cesium surface concentration (as seen in Fig. 9).

$\mathrm{H}^{-}$generation is also sensitive to hydrogen flow variation (curve 2 in Fig. 8).

The ratio of $I_{\mathrm{fc}} / P_{\mathrm{rf}} \sim 1.6 \mathrm{~mA} / \mathrm{kW}$, produced before cracking the cesium ampoule, is higher than in other rf discharges in similar cesium-free conditions.

Nanograms of ILIP are enough to enhance secondary emission of negative ions from the collar surface. This process efficiently works for other ILIP such as K, Na, Ba, La... [7,20]. This activation from contamination was so perfect that the efficiency of $\mathrm{H}^{-}$generation was not improved significantly by standard cesiation after cracking the cesium ampoule. The small contamination of ceramic such as $0.01 \%$ of $\mathrm{K}_{2} \mathrm{O}$ can be enough for domination of the SPG above volume generation in the other "volume" rf sources $[7,10]$.

\section{Beam chopping}

With a narrow slit emission aperture and narrow beam, it is possible to have a fast and flexible deflection of the ion 


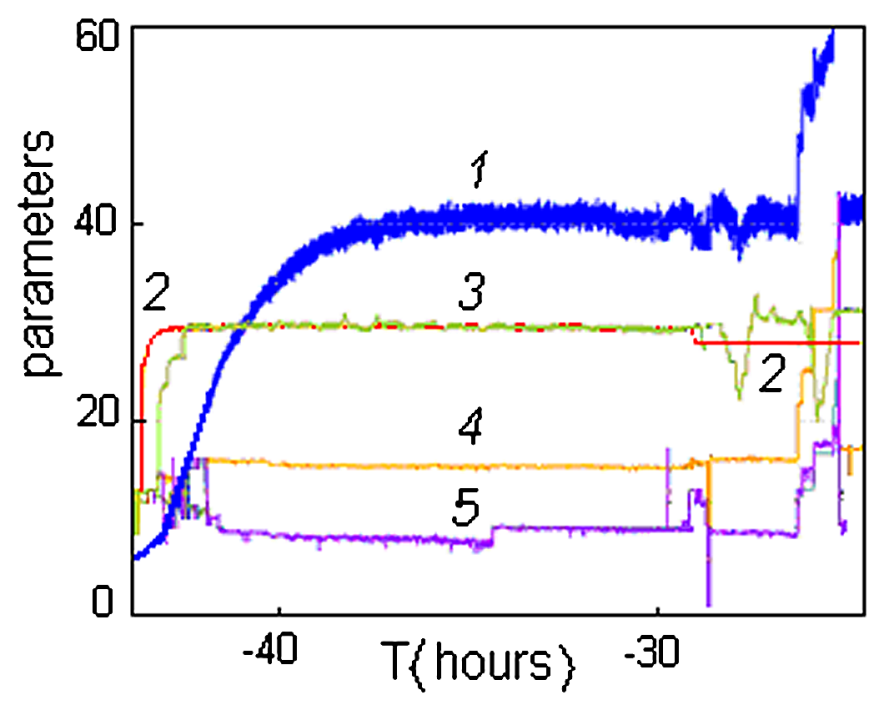

FIG. 8. Evolution of $\mathrm{H}^{-}$beam intensity of the saddle antenna rf LV SPS; (1) ion beam current; (2) gas flow; (3) collar temperature; (4) forward rf power; (5) reflected rf power.

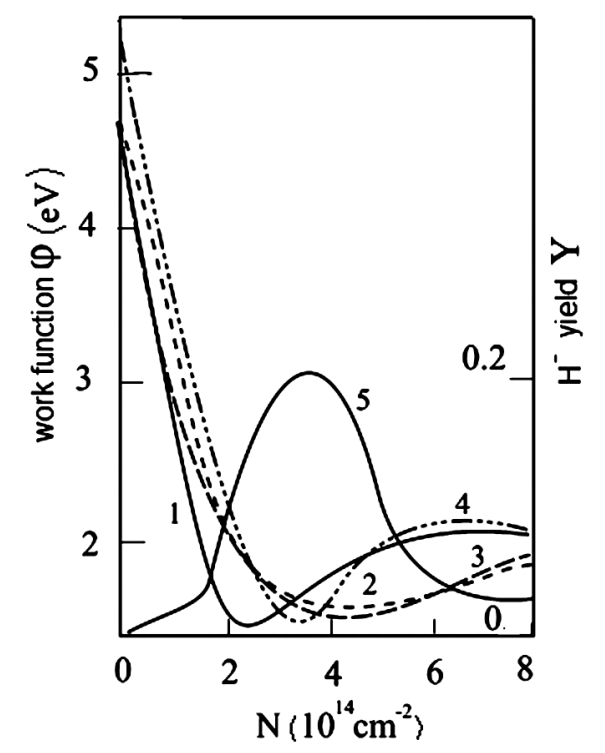

FIG. 9. Dependences of work function on surface cesium concentration for different $W$ crystalline surfaces [(1)-(001); (2)—(110); (3)—(111); (4)—(112), left scale] and (5) relative yield $Y$ of $\mathrm{H}^{-}$secondary emission for surface index (111), right scale.

beam necessary for ion beam distribution. For narrow beam deflection it is possible to use relatively short deflector plates (19 in Fig. 5) or a short traveling wave deflector with relatively low voltage for very fast (nanosecond) beam deflection as in fast cathode ray tube oscilloscopes. Fast beam chopping by such an extractor was tested in [14] to create $150 \mathrm{~ns}$ notches. Slower ( $\sim 50 \mathrm{~ns})$ beam manipulation connected with space-charge neutralization was also performed.
With a smaller beam size $(\sim 3-5 \mathrm{~mm})$, it is possible to have chopping with $t \sim 3-5$ ns rise time with relatively low deflection voltage, which is important for reliable long term operation. Deflecting plate designs and deflecting electronics from fast oscilloscopes can be used for this application. $\mathrm{H}^{-}$beam focusing by a special electrostatic lens was demonstrated successfully for $\mathrm{H}^{-}$beams with current up to $15 \mathrm{~mA}$ [22]. With this focusing, the rise and fall time of the chopped beam will be independent of space-charge neutralization.

Another possibility for fast beam chopping is to use photodetachment of electrons from $\mathrm{H}^{-}$ions by laser pulses after extraction. $\mathrm{H}^{-}$ions with energy $W \sim 10 \mathrm{keV}$ have velocity $V \sim 10^{8} \mathrm{~cm} / \mathrm{s}$ and for a time gap of $1 \mathrm{~ns}$ it is needed to neutralize $\sim 1 \mathrm{~mm}$ of ribbon beam with transverse cross section $\sim 1 \times 10 \mathrm{~mm}$. The photodetachment cross section is $\sigma=2 \times 10^{-17} \mathrm{~cm}^{2}$ for photons with wavelength $\lambda=$ $1 \mu \mathrm{m}$. The differential probability of photodetachment of $\mathrm{H}^{-}$in a flux of photons with density $c n$ is proportional to $\sigma n c$. For $\mathrm{H}^{-}$ion neutralization with $90 \%$ probability it is needed to accumulate an integral flux density $n c t$ with $\sigma n c t=3$. The corresponding integral flux density is $n c t=$ $1.5 \times 10^{17}$ photons $/ \mathrm{cm}^{2}$ and the corresponding energy density is $P \sim 2.5 \times 10^{-2} \mathrm{~J} / \mathrm{cm}^{2}$. In a beam with a required cross section of $1 \times 1 \mathrm{~mm}^{2}$, an energy of $E \sim 2.5 \times$ $10^{-4} \mathrm{~J} /$ pulse is needed. For beam chopping with a frequency $f=100 \mathrm{MHz}$, it is necessary to have a $1 \mu \mathrm{m}$ laser with $\mathrm{cw}$ reactive power $\mathrm{Pr} \sim 25 \mathrm{~kW}$ in a resonator with a high quality $Q$. For $Q \sim 10^{3}$ the active energy loss $\mathrm{Pa} \sim$ $25 \mathrm{~W}$ can be compensated by diode laser pumping.

\section{PRODUCTION OF SURFACES WITH LOW WORK FUNCTION}

For stable and reproducible $\mathrm{H}^{-}$ion generation in a SPS, it is necessary to perform special cleaning and processing of the electrode surfaces. For reproducible production of surfaces with low work function, it is necessary to heat them to high temperatures for long times to remove volume impurities. Fortunately, from the beginning there has been the possibility for high temperature $(>1500 \mathrm{~K})$ heating of SPS by discharges. Discharges with air were used for electrode cleaning from cesium and from carbon $[2,4]$. Some procedures for production of low work function in systems similar to SPS with cesiation are discussed below.

The dependence of work function on surface cesium concentration for different tungsten crystalline surfaces at low temperatures is shown in Fig. 9. The dependence of the relative yield $Y$ of $\mathrm{H}^{-}$secondary emission on cesium surface density is shown by curve 5 .

The relative dependence of desorption energy $H(N)$ on surface cesium concentration $N$ for different $W$ crystalline surfaces is shown in Fig. 10. The relative dependences for molybdenum are very similar. On a polycrystalline material surface a combination of related conditions coexists. On very clean surfaces with work function above $4 \mathrm{eV}$, the 


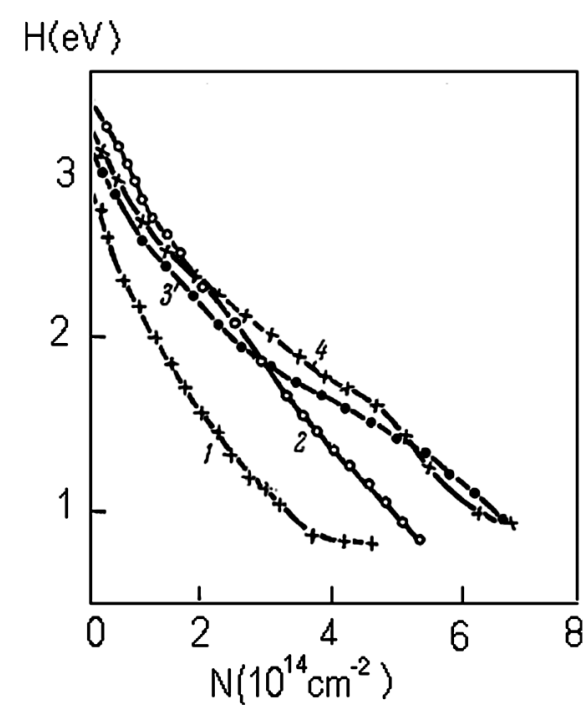

FIG. 10. Dependence of desorption energy $\mathrm{H}$ on surface cesium concentration $N$ for different $W$ crystalline surfaces [(1)—(001); (2)—(110); (3)—(111); (4)—(112)].

yield of secondary emission of $\mathrm{H}^{-}$ions is very low $\left(\sim 10^{-4}\right.$ for fast bombarding particles) and volume generation of $\mathrm{H}^{-}$can dominate in these conditions. With increasing surface concentration of low ionization potential (LIP) particles up to $N \sim 10^{14} \mathrm{p} / \mathrm{cm}^{2}\left(\sim 10 \mathrm{ng} / \mathrm{cm}^{2}\right)$ the work function drops below $2 \mathrm{eV}$ and $Y$ increases significantly, reaching a maximum of $Y \sim 0.2$ with a minimum work function $\sim 1.5 \mathrm{eV}$ and surface concentration of LIP particles of $N \sim 2-4 \times 10^{14} \mathrm{p} / \mathrm{cm}^{2}\left(\sim 30 \mathrm{ng} / \mathrm{cm}^{2}\right)$.

The desorption energy of cesium decreases almost linearly with surface cesium concentration from $H \sim 3 \mathrm{eV}$ for a clean surface to $H<1 \mathrm{eV}$ at a surface concentration of LIP particles of $N \sim 4-6 \times 10^{14} \mathrm{p} / \mathrm{cm}^{2}$ $\left(\sim 50 \mathrm{ngram} / \mathrm{cm}^{2}\right)$, approximately consisting of one monolayer.

The thermal desorption time $\tau$ has an exponential dependence on $\mathrm{H}$ and temperature $T$ :

$$
\begin{aligned}
\tau(N) & =\tau_{\mathrm{o}} \cdot \exp [H(N) / k \cdot T] \\
& =5 \times 10^{-13} \cdot \exp [H(N) / k \cdot T][\mathrm{s}] .
\end{aligned}
$$

For low $T<500 \mathrm{~K}, H \sim 1.5 \mathrm{eV}$, equal to $1.5,10^{4} \mathrm{~K}, \tau$ is above several seconds, where LIP impurities can be accumulated for long times, an optimal concentration can be supported by very small flux density.

An equilibrium cesium concentration on the surface depends on Cs particle flux to the surface from the volume and on the rate of desorption determined by $\tau$. In a system with a cesium supply, such as thermionic energy converters, the Cs particle flux to the surface from the volume has an exponential dependence on Cs reservoir temperature $\mathrm{Tr}$ and the equilibrium cesium concentration on the surface depends on ratio $\mathrm{T} / \mathrm{Tr}$. The optimum Cs concentration delivering the minimal work function corresponds to $\mathrm{T} / \mathrm{Tr} \lesssim 2$.

In SPS this equilibrium is complicated by fast particle sputtering and Cs ion trapping by the plasma. However, Cs adsorbate sputtering by hydrogen ions is low up to energy of about $50 \mathrm{eV}$ because of the big mass ratio. But desorption by heavier fast particles can be more important. An additional complication is an impurity deposition which is strong in SPS with hot cathode discharge that necessitates Cs redeposition. The suppression of electrode sputtering by backaccelerated positive ions is important to minimize cesium consumption. Recently, these effects have been seen to be more favorable in SPS with rf plasma generation for operation with very low cesium consumption as was demonstrated in $[24,25]$ and in this report. With an internal Cs supply, proper cesiation can be done in about 20 minutes [24].

The desorption energies of other LIP such as $\mathrm{Rb}, \mathrm{K}, \mathrm{Na}$, $\mathrm{Ba}$, and $\mathrm{La}$ are larger and the optimal concentration of these LIP substances can be supported by lower flux from the volume or by one time deposition.

The increase of $\mathrm{H}^{-}$generation with decrease of collar temperature below $T \sim 540 \mathrm{~K}$ confirms the existence of a Cs flux to the collar surface from a parasitic Cs supply corresponding to $\operatorname{Tr} \sim 340 \mathrm{~K}$. At a lower collar temperature, the optimal Cs concentration $N$ can be supported at lower $\operatorname{Tr}$ with a lower flux of cesium.

Further lowering of the work function can be produced (at least in vacuum conditions) by coadsorption of electronegative impurities such as oxygen or fluorine as shown in

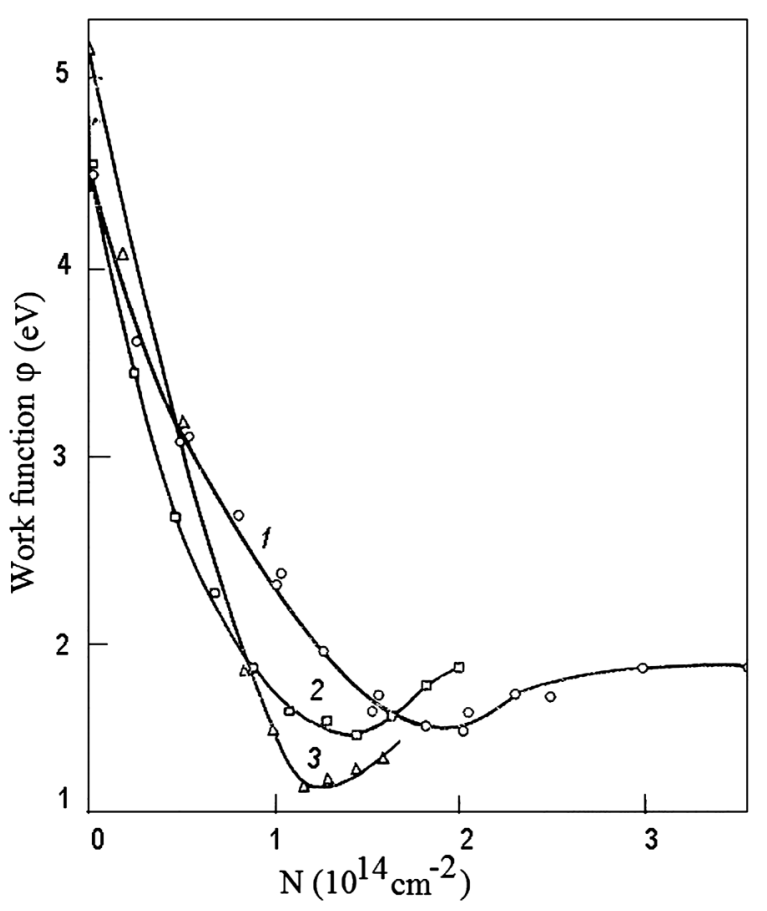

FIG. 11. Dependence of work function on surface cesium concentration for a $W$ surface with different oxygen concentrations: (1) clean surface; (2) low oxygen concentration; (3) high oxygen concentration (increase of work function up to $5.3 \mathrm{eV}$ ). 


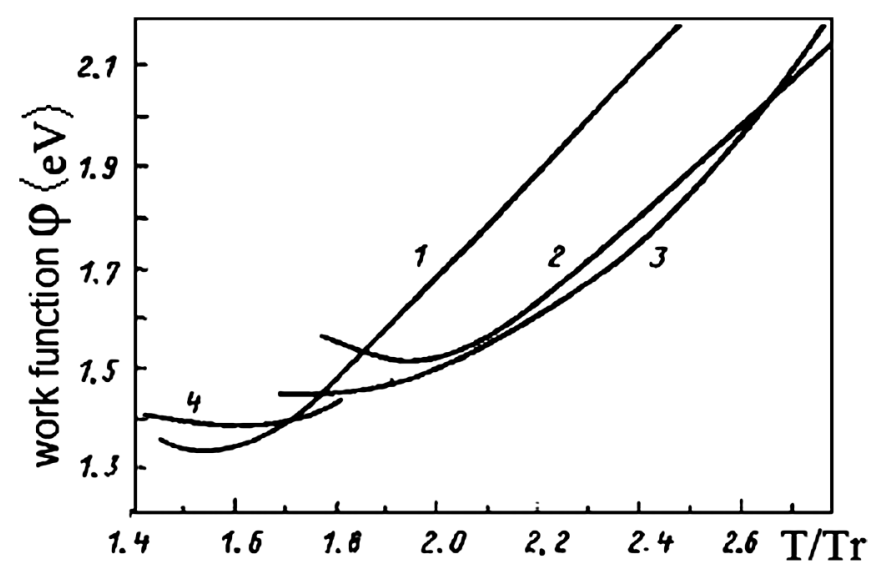

FIG. 12. The work function in the case of cesium adsorption dependence upon the ratio of sample temperature $T$ to cesiumtank temperature $\mathrm{Tr}$ for collectors of (1) a molybdenum polycrystalline with a tungsten layer on the surface, (2) (110) molybdenum, (3) a molybdenum polycrystalline, and (4) an $\mathrm{LaB}_{6}$ polycrystalline [25].

Fig. 11. Cesium deposition to the slightly oxidized surface (curve 2) decreases the work function faster than during deposition to clean surface (curve 1). After stronger oxidizing it is possible to have a smaller minimum work function at lower Cs surface density (curve 3). However, the minimization of the work function is not always successful. In Cs deposition to polycrystalline molybdenum in Ref. [26] the minimum work function was not reached but a decrease of work function from 4.4 to $2.8 \mathrm{eV}$ was observed.

Variation of work functions influences very much the efficiency of $\mathrm{H}^{-}$ion production. Production of reproducible low work functions has been developed in photocathode manufacturing and in thermionic convertors [27].
This procedure can be used for electrode activation in the SPS. Figure 12 shows the dependence of work functions for molybdenum and $\mathrm{LaB}_{6}$ surfaces as a function of the surface temperature $\mathrm{T}$ to $\mathrm{Cs}$ container temperature ratio $(\mathrm{T} / \mathrm{Tr})$ from [25]. Tungsten deposition does not prevent production of a work function below $1.5 \mathrm{eV}$, which is very favorable for highly efficient $\mathrm{H}^{-}$generation.

The features of cesiation optimization discussed above are also applicable to surface plasma generation of negative ions in nuclear polarized atomic beam negative ion sources, which are considered below.

\section{CESIATION IN POLARIZED NEGATIVE ION PRODUCTION}

Properly optimized cesiation is important for efficient generation of $\mathrm{H}^{-} / \mathrm{D}^{-}$for resonant charge-exchange ionization of nuclear polarized atoms of H/D in atomic beam polarized ion sources (ABPIS).

The most advanced version of the ABPIS with ionization of polarized atoms by resonant charge exchange with cold negative ions produced on cesiated converter was proposed in [28] and was developed at the Institute of Nuclear Research (INR) [29,30]. A schematic diagram of the ABPIS reproduced in Indiana University Cyclotron Facility [31] is shown in Fig. 13.

A polarized atomic beam source with selective resonant charge-exchange ionization has a good potential to produce $\mathrm{H}^{-} / \mathrm{D}^{-}$ion beams with the highest polarization [29,30]. Low-energy unpolarized $\mathrm{H}^{-} / \mathrm{D}^{-}$ions can transfer electrons only to $H$ or $D$ atoms but not to molecules. This method of ionization allows one to produce $\mathrm{H}^{-} / \mathrm{D}^{-}$ion beam polarization higher than that of the atomic beam by eliminating unpolarized molecules from the beam. A pulsed mode of operation is favorable for high-intensity

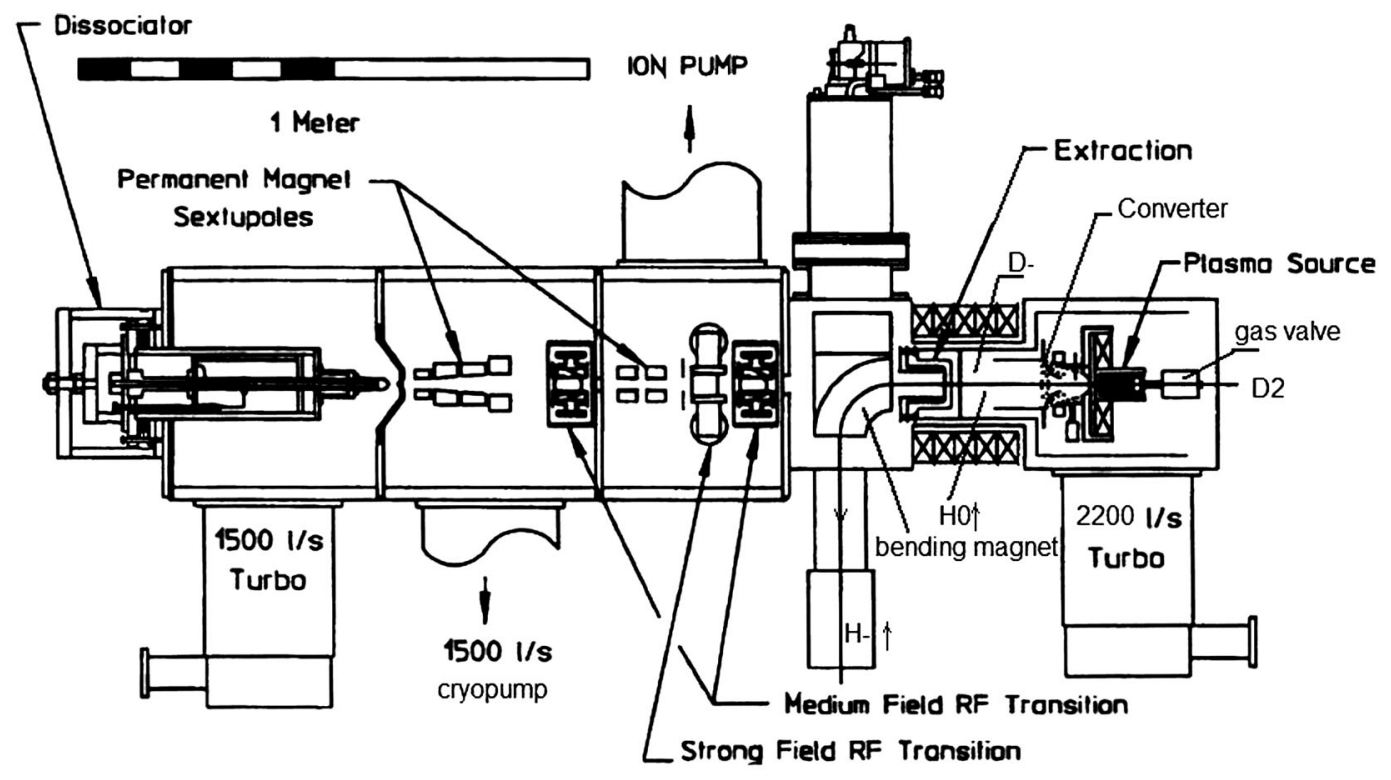

FIG. 13. Schematic diagram of ABPIS with resonant charge-exchange ionization [31]. 
and high-polarization production. An efficient pulsed operation can be attained using a fast gas valve [13] and a small-volume rf discharge dissociator with a helicon antenna in a magnetic field (a new design of the dissociator).

In the ABPIS, hydrogen or deuterium atoms are formed by the dissociation of molecular gas, typically in an $\mathrm{rf}$ discharge dissociator. The atomic flux is cooled to a temperature of 30 to $80 \mathrm{~K}$ by passing the atoms through a cryogenically cooled nozzle. The atoms escape from the nozzle orifice into the vacuum and are collimated to form a beam. The beam passes through a region with an inhomogeneous magnetic field created by sextupole magnets where atoms with one orientation of the electron spin relative to the magnetic field are focused while atoms with the opposite orientation of the electron spin are defocused. Nuclear polarization of the beam is increased by inducing transitions between the spin states of the atoms. The rf transition units are also used for fast reversal of the nuclear spin direction without changing the atomic beam intensity and divergence. The main components of this ABPIS shown in Fig. 13 are: (i) Source of the polarized atomic $\mathrm{H}$ or $\mathrm{D}$ beam (left); (ii) surface-plasma source of the cold unpolarized negative $\mathrm{D}^{-}$or $\mathrm{H}^{-}$ions with an arcdischarge plasma source and a surface-plasma ionizer with cesiated converter (right); (iii) charge-exchange solenoid with a grid extraction system (middle); (iv) deflecting magnet for separation of the polarized and unpolarized $\mathrm{H}^{-}$ and $D^{-}$beams (transition to the bottom part); (v) beam line and polarimeter (bottom part). The online measurement of the polarization is very important for optimization of many parameters influencing the polarization.

Several schemes using sextupole magnets and rf transition units have been used in the hydrogen or deuterium ABPIS. For atomic hydrogen, a typical scheme consists of two sextupole magnets followed by medium-field and strong-field rf transition units. In this case, the theoretical proton polarization will reach $P z= \pm 1$. Switching between the two $P z= \pm 1$ states is performed by switching between operation of the weak-field and strong-field $\mathrm{rf}$ transition units. For atomic deuterium, two sextupole magnets and three rf transitions are used in order to get deuterons with vector polarization of $P z= \pm 1$ and tensor polarization of $P z z=+1,-2$. The polarized atomic beam intensity is proportional to the solid angle $\Delta \Omega=\pi \alpha^{2}$, where an angle aperture $\alpha$ is determined by the magnetic focusing system and magnetic field.

Different methods for ionizing polarized atoms and their conversion into negative ions were developed in many laboratories. The techniques depended on the type of accelerator where the source was used and the required characteristics of the polarized ion beam. For the pulsed atomic beam polarized ion source (ABPIS), the most efficient method was developed at INR, Moscow [29]. Polarized hydrogen atoms at thermal energy are injected into an ionizer solenoid with an incident flux of deuterium plasma where polarized protons or negative hydrogen ions are formed due to the quasiresonant charge-exchange reactions:

$$
\begin{array}{ll}
\mathrm{H}^{0} \uparrow+\mathrm{D}^{+} \Rightarrow \mathbf{H}^{+} \uparrow+\mathrm{D}^{0} & \mathrm{D}^{0} \uparrow+\mathrm{H}^{+} \Rightarrow \mathbf{D}^{+} \uparrow+\mathrm{H}^{0} \\
\mathrm{H}^{0} \uparrow+\mathrm{D}^{-} \Rightarrow \mathbf{H}^{-} \uparrow+\mathrm{D}^{0} & \mathrm{D}^{0} \uparrow+\mathrm{H}^{-} \Rightarrow \mathbf{D}^{-} \uparrow+\mathrm{H}^{0} .
\end{array}
$$

In an ABPIS, a $\mathrm{D}^{+}$plasma jet emerging from an arcdischarge source [32] is converted into a low-energy $\mathrm{D}^{-}$ ion jet in a surface plasma ionizer. The designs of the surface plasma (SP) ionizer (INR version) are shown in Figs. 13 and 14. The first cesiated converter for negative ion generation was proposed by Dudnikov [28] and was further optimized with Belov [29-31].

The most recent version of an unpolarized $\mathrm{H}^{-} / \mathrm{D}^{-}$ source with two-step surface plasma ionizer is shown in Fig. 14.

By using resonant charge-exchange ionization, it is possible to have an efficiency of nuclear polarized atom to polarized $\mathrm{H}^{-} / \mathrm{D}^{-}$transformation of over $12 \%$ instead of about $0.1 \%$ for older ionization methods. The high selectivity of polarized atom ionization allows polarization above 0.9. An arc-discharge plasma source developed at BINP [31] is used as a plasma jet generator. A converter with cesium deposition is used for conversion of the plasma flux into cold negative ions. The efficiency of $\mathrm{D}^{+}$ to $\mathrm{D}^{-}\left(\mathrm{H}^{+}\right.$to $\left.\mathrm{H}^{-}\right)$conversion depends on the cesium surface density (or work function) as shown in Fig. 9 from $\sim 10^{-4}$ at very low Cs density to $\sim 0.2$ at optimal Cs density delivering a minimal work function. It is important to be able to prepare the surfaces by heating them to high temperature, activating by plasma, and depositing the optimal amount of cesium as discussed above. The gas is injected into the arc-discharge source by the fast pulsed valve [13]. The plasma jet with ionization of $\sim 99 \%$ from the arc-discharge source with cold cathode and diaphragm discharge channel is then collimated by the solenoid

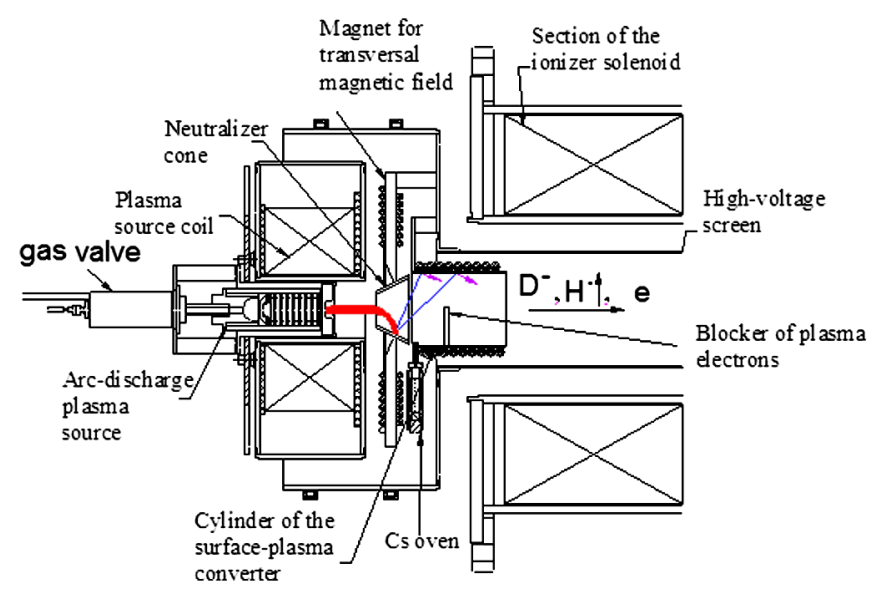

FIG. 14. Generation of a cold $\mathrm{D}^{-}$plasma jet for resonant charge-exchange negative ionization of polarized hydrogen atoms (INR version) [30]. 
magnetic field and directed by a transverse magnetic field to the internal surface of the neutralizer cone of the converter with a small negative potential. In this step the ions of the plasma jet are converted to atoms with several $\mathrm{eV}$ of energy. The reflected atoms bombard the internal cesiated surface of the cylindrical part of surface plasma converter and are transformed into reflected cold negative ions. Unpolarized $\mathrm{H}^{-} / \mathrm{D}^{-}$currents up to $60 / 100 \mathrm{~mA}$ were produced, extracted, and registered after the bending magnet with this ionizer. The coextracted electron current was decreased by a blocker collecting the central part of the plasma electron jet. Polarized $\mathrm{H}^{-} / \mathrm{D}^{-}$currents were increased up to $4 \mathrm{~mA}$ with measured polarization up to 0.91 [30]. For high polarization it is important to prevent negative ion production from nuclear depolarized atoms adsorbed on the converter surface. For this it is necessary to prevent the polarized beam adsorption on all surfaces of the surface plasma ionizer. The temperature of the ionizing components can be elevated and optimized for this purpose.

The development and adaptation of a high-polarization ABPIS promises to improve the productivity of very costly polarized colliding beam experiments at RHIC and is crucial for the electron-ion colliders under development at Jefferson Laboratory and at BNL.

\section{SUMMARY}

A comprehensive review of the development of $\mathrm{H}^{-}$ion sources for accelerators and of the status of different $\mathrm{H}^{-}$ sources up to 2005 was presented in [8]. Since then, the operation of the SNS $\mathrm{H}^{-}$source with internal rf antenna developed by LBNL was improved significantly by modifications to the short electrostatic LEBT, which suppressed sparking [24]. After the optimization of the collar for surface plasma generation of $\mathrm{H}^{-}$around the $7 \mathrm{~mm}$ diameter emission aperture and improving the cesiation, stable production of pulsed $\mathrm{H}^{-}$beam with $\sim 40 \mathrm{~mA}$ intensity at $6 \%$ duty factor (2.5 $\mathrm{mA}$ average current) was established for 2-3 weeks runs with small $(\mathrm{mg})$ cesium consumption [24]. However, even after these improvements the efficiency of $\mathrm{H}^{-}$generation was still relative low $\sim 1 \mathrm{~mA} / \mathrm{kW}$ of rf power and further increases of beam current and lifetime to $2.5 \mathrm{~mA} \times 500 \mathrm{~h}$ or $1.3 \mathrm{~A}$-hrs are problematic. As was remarked above, the efficiency of a magnetron SPS is about $60 \mathrm{~mA} / \mathrm{kW}$ and the efficiency of a PD SPS is $10-20 \mathrm{~mA} / \mathrm{kW}$ with straightforward production of pulsed $\mathrm{H}^{-}$beam with intensity $\sim 0.1 \mathrm{~A}[8,17,18]$. In a cw PD SPS, stable average production of $18 \mathrm{~mA} \mathrm{H}^{-}$beam was demonstrated for about 200 hours for about 3.6 A-hrs [22]. These results imply an excellent opportunity to develop a compact SPS with higher average pulsed $\mathrm{H}^{-}$ current and a longer lifetime. Such a compact SPS can have a simple design with a less expensive power supply, which will decrease ownership cost and improve commercial attractiveness.
The efficiency, lifetime, and $\mathrm{H}^{-} / \mathrm{D}^{-}$ion polarization can be improved by further optimization of cesiation in the atomic beam polarized ion sources with resonance charge-exchange ionization as discussed above.

Laser diagnostics of cesium dynamic in the SPS proposed in Ref. [23] can be used for improving of cesiation.

\section{ACKNOWLEDGMENTS}

This work was supported in part by U.S. DOE STTR Grant No. DE-SC0002690.

[1] V. Dudnikov, SU Author Certificate, C1.H01 3/04, No. 411542, 1972 [http://www.fips.ru/cdfi/reestr_rupat.htm].

[2] V. Dudnikov, Doctoral thesis, INP, Novosibirsk, 1977.

[3] V. Dudnikov, Rev. Sci. Instrum. 63, 2660 (1992); Rev. Sci. Instrum. 73, 992 (2002).

[4] V. Dudnikov, in Proceedings of 4th All-Union Conference on Charged Particle Accelerators, Moscow, 1973 (NAUKA, Moscow, 1974), Vol. 1, p. 323; LASL, LATR-75-4, 1975.

[5] Yu. I. Belchenko, G. I. Dimov, and V.G. Dudnikov, in Proceedings of the Symposium on the Production and Neutralization of Negative Hydrogen Ions and Beams, Brookhaven, 1977 (BNL, Upton, NY, 1977), Vol. 50727, pp. 79-96.

[6] Charles W. Schmidt, Linac 1990 (LA-12004-C), 1990, p. 259 [http://ccdb4fs.kek.jp/cgi-bin/img/allpdf? 199104233].

[7] J. Peters, Rev. Sci. Instrum. 71, 1069 (2000); in Negative Ions, Beams and Sources, edited by E. Surrey and A. Simonin, AIP Conf. Proc. No. 1097 (American Institute of Physics, Melville, NY, 2009), pp. 236-242.

[8] D. P. Moehs, J. Peters, and J. Sherman, IEEE Trans. Plasma Sci. 33, 1786 (2005).

[9] Yu. Belchenko and V. Dudnikov, J. Phys. (Paris) 40, 501 (1979).

[10] Zhang Hua Shun, Ion Sources (Springer, New York, 1999).

[11] Dudnikov et al., Rev. Sci. Instrum. 73, 989 (2002).

[12] H. V. Smith et al., Rev. Sci. Instrum. 65, 123 (1994).

[13] G. E. Derevyankin, V. G. Dudnikov, and P. A. Zhuravlev, Prib. Tekh. Eksp. 5, 168 (1975).

[14] D. P. Moehs, AIP Conf. Proc. 925, 361 (2007).

[15] P. Allison, IEEE Trans. Nucl. Sci. 24, 1594 (1977); Rev. Sci. Instrum. 58, 235 (1987).

[16] R. Sidlow et al., EPAC 96, 1996, Vol. 96, THP084L [http://accelconf.web.cern.ch/AccelConf/e96/PAPERS/ THPL/THP084L.PDF].

[17] Dan Faircloth et al., Rev. Sci. Instrum. 81, $02 \mathrm{~A} 721$ (2010).

[18] G. Dimov, G. Derevyankin, and V. Dudnikov, IEEE Trans. Nucl. Sci. 24, 1545 (1977).

[19] K. Leung, K. Ehlers, P. Alisson, and V. Shmidt, AIP Conf. Proc. 158, 356 (1987); K. Leung, K. Ehlers, P. Alisson, and V. Shmidt, Rev. Sci. Instrum. 58, 235 (1987). 
[20] A. Ueno, K. Ikegami, and Ya. Kondo, Rev. Sci. Instrum. 75, 1714 (2004); H. Oguri, A. Ueno, and K. Ikegami, Rev. Sci. Instrum. 79, 02A506 (2008).

[21] A. Ueno, H. Oguri, K. Ikegami, Y. Namekawa, and K. Ohkoshi, Rev. Sci. Instrum. 81, 02 A720 (2010).

[22] Yu. Belchenko A. Sanin, and A. Ivanov, in Negative Ions, Beams and Sources (Ref. [7]), pp. 214-222.

[23] A. Dudnikov et al., Rev. Sci. Instrum. 81, $02 \mathrm{~A} 714$ (2010).

[24] Martin P. Stockli, B. Han, S. N. Murray, T. R. Pennisi, M. Santana, and R.F. Welton, in Negative Ions, Beams and Sources (Ref. [7]), pp. 223-235.

[25] V. Dudnikov, Rolland P. Johnson, Martin P. Stockli, B. Han, S. N. Murray, T. R. Pennisi, M. Santana, and R. F. Welton, IPAC 2010, Kyoto, Japan (American Institute of Physics, Melville, NY, 2010), THPEC073.
[26] U. Fantz, R. Gutser, and C. Wimmer, Rev. Sci. Instrum. 81, 02B102 (2010).

[27] V. Z. Kaibyshev, V. A. Koryukin, and V. P. Obrezumov, At. Energ. 69, 800 (1990).

[28] A.S. Belov et al., in Proceedings of the Symposium on the Production and Neutralization of Negative Hydrogen Ions and Beams, AIP Conf. Proc. No. 287, edited by J. Alessi and A. Hershkovitch (AIP, New York, 1994), p. 485.

[29] A. S. Belov et al., Nucl. Instrum. Methods Phys. Res., Sect. A 333, 256 (1993).

[30] A. Belov, AIP Conf. Proc. 980, 209 (2008).

[31] A.S. Belov and V.P. Derenchuk, Jefferson Laboratory, 2003 ICFA Beam Dynamics Newsletter (2003).

[32] Yu. Bel'chenko, V. Davydenko, G. Dimov, and V. Dudnikov, Rev. Sci. Instrum. 61, 378 (1990). 